\title{
Influence of Cellular and Plasma Procoagulant Activity on the Fibrin Network
}

\author{
Alisa S. Wolberg ${ }^{*}$ and Maria M. Aleman \\ Department of Pathology and Laboratory Medicine, University of North Carolina at Chapel Hill, \\ Chapel Hill, NC 27599-7525
}

\begin{abstract}
At the nexus of cellular and plasma procoagulant activities lies fibrin, which is necessary to provide a clot's structural support. Abnormalities in fibrin network formation or function can result in either bleeding or thrombotic complications. Understanding relationships between procoagulant activity and normal fibrin formation, as well as pathophysiologic mechanisms leading to abnormal fibrin deposition, is essential for the continued development of hemostatic and antithrombotic therapies.
\end{abstract}

\author{
Keywords \\ fibrinogen; tissue factor; thrombin; thrombosis; plasma
}

\section{Introduction}

Blood coagulation involves contributions from the cells, plasma, and blood flow (shear rates) present within the vasculature. At the nexus of these components lies fibrin, which is essential to support the primary platelet plug and prevent premature disruption of the clot (Figure 1). Deficiencies in fibrin production result in bleeding diatheses, while the formation of overlystable fibrin networks is associated with prothrombotic pathologies. Identifying the biochemical and biophysical contributions of vascular cells, plasma proteins, and shear to fibrin production is essential for understanding mechanisms operant in hemostasis and thrombosis.

\section{Brief Review of Fibrin(ogen) Biochemistry}

Fibrinogen is a $340 \mathrm{kDa}$ glycoprotein circulating at $6-12 \mu \mathrm{M}(2-4 \mathrm{mg} / \mathrm{ml})$. It is synthesized in the liver and consists of two pairs each of three polypeptide chains: $\mathrm{A} \alpha, \mathrm{B} \beta$, and $\gamma$, physically arranged with their $\mathrm{N}$-termini in the center of the elongated molecule. Proteolytic release of $\mathrm{N}$-terminal peptides, exposure of new $\mathrm{N}$-termini in the $\mathrm{A} \alpha$ and $\mathrm{B} \beta$ chains, and insertion of the $\mathrm{N}$-termini into structural pockets in the $\gamma$ and $\mathrm{B} \beta$ chains, respectively, of fibrin monomers enable the end-to-end polymerization into protofibrils, lateral association into fibers, and formation of the fibrin network.[1] The conditions under which the network forms, including

(C) 2009 Elsevier Ltd. All rights reserved

*Address for correspondence: Alisa S. Wolberg, Ph.D. Department of Pathology and Laboratory Medicine University of North Carolina at Chapel Hill 815 Brinkhous-Bullitt Building CB \#7525 Chapel Hill, NC 27599-7525 Telephone: (919) 966-8430 Fax: (919) 966-6718 alisa_wolberg@med.unc.edu.

Publisher's Disclaimer: This is a PDF file of an unedited manuscript that has been accepted for publication. As a service to our customers we are providing this early version of the manuscript. The manuscript will undergo copyediting, typesetting, and review of the resulting proof before it is published in its final citable form. Please note that during the production process errors may be discovered which could affect the content, and all legal disclaimers that apply to the journal pertain.

Conflict of Interest ASW has received research funding from Novo Nordisk A/S. 
the local $\mathrm{pH}$ and concentrations of thrombin, calcium, and polyphosphate determine its physical and biochemical properties.[2,3] In particular, low thrombin concentrations produce thick fibrin fibers assembled into coarse networks that are relatively susceptible to fibrinolysis, whereas higher thrombin concentrations promote the formation of thin fibrin fibers assembled into dense networks that are relatively resistant to fibrinolysis.[4]

\section{Regulation of Thrombin Generation during Hemostasis and Thrombosis}

During hemostasis, exposure of subendothelial tissue factor (TF) to blood triggers coagulation. The current conceptual model of coagulation describes three phases of procoagulant activity: initiation, amplification, and propagation. [5] In the initiation phase, the factor VIIa/TF complex converts factors IX to IXa and X to Xa. Amplification involves extrinsic and prothrombinase activities on TF-bearing cells that promote small-scale thrombin generation to activate cofactors V and VIII, factor XI, and platelets. The activated platelet subsequently provides a highly procoagulant surface for the propagation phase of coagulation. On the platelet surface, factor IXa (with its cofactor VIIIa) activates factor X, which becomes incorporated into platelet prothrombinase for large-scale thrombin generation necessary for efficient conversion of fibrinogen to fibrin. Thrombin generation during this process exhibits complex kinetics, with a lag phase (initiation and amplification), maximum burst and peak phase (propagation) and subsequent decline to baseline values (thrombin inhibition by antithrombin and $\alpha 2$ macroglobulin).

These same procoagulant processes are initiated in arterial thrombosis following plaque rupture that exposes TF from the plaque's necrotic core (reviewed in [6]). Similarly, venous thrombosis is thought to arise from inappropriate expression of intravascular TF on an intact endothelium, or from circulating TF-bearing procoagulant microvesicles released from activated vascular cells. [7] The ability of thrombolytic therapy to dissolve fibrin in both arterial and venous thrombi and restore blood flow demonstrates the crucial role of fibrin in both of these pathologies.

\section{Contributions of Cells, Plasma, and Blood Flow on Thrombin Generation and Fibrin Formation}

Previous studies have shown complex effects of cells, plasma, and blood flow on thrombin generation and fibrin formation. Each of these components can both promote clotting by increasing procoagulant activity or inhibit clotting by limiting procoagulant activity at the site of clotting. The remainder of this review will focus on cellular and soluble (plasma) contributions to thrombin generation and their effects on fibrin properties.

\section{Contributions of Cells to Thrombin Generation and Fibrin Formation, Structure and Stability}

During both hemostatic and thrombotic clot formation, cells provide the initiating trigger of coagulation (TF), procoagulant and anticoagulant proteins that regulate thrombin generation, and a procoagulant surface upon which these reactions occur. In general, extravascular cells tend to support high procoagulant activity in their basal state, whereas intravascular cells remain quiescent in a predominantly anticoagulant state until stimulated during infection or inflammation. We and others have shown cellular procoagulant activity dictates fibrin network formation, structure, and resistance to fibrinolysis).[8-10] Procoagulant extravascular cells (e.g., cultured fibroblasts and smooth muscle cells) support the rapid formation of dense fibrin networks that resist fibrinolysis. In contrast, unstimulated intravascular cells (cultured endothelial cells) only slowly produce open networks that are susceptible to fibrinolysis, likely an artefact of low levels of TF expression on cultured cells.[10] These findings are consistent with the current view of hemostasis, whereby intravascular cells in contact with blood suppress 
thrombin generation and fibrin formation, but vascular breach and exposure of procoagulant extravascular cells to blood rapidly initiates formation of a stable fibrin network to reinforce the primary platelet plug and support hemostasis.

Inappropriate expression of cellular procoagulant activity is thought to promote intravascular clotting and development of venous thromboembolism. Pro-inflammatory mediators, including bacterial lipopolysaccharide and certain proinflammatory cytokines, including interleukin- $1 \beta$ and tumor necrosis factor-alpha (TNF $\alpha)$, induce procoagulant activity in cultured endothelial cells by increasing TF and decreasing thrombomodulin expression in a time- and dose-dependent manner.[11] We have found that TNF $\alpha$-stimulated endothelial cells promote formation of a fibrin network that has increased density and stability compared to that produced by unstimulated endothelial cells.[10]

The ability of each of these cells to promote thrombin generation is positively correlated with their expression of TF.[8,10] Fibroblasts express high levels of TF, smooth muscle cells and $\mathrm{TNF} \alpha$-stimulated endothelial cells express moderate TF activity, and unstimulated endothelial cells express low to no TF activity. The density and stability of fibrin networks produced by these cells are also positively correlated with the level of cellular TF activity.[10] Accordingly, inhibiting TF activity on TNF $\alpha$-stimulated endothelial cells reduces the density and stability of fibrin networks to that produced by unstimulated cells.[10] These in vitro findings are supported by experiments with genetically-manipulated mice. Mice with decreased ability to regulate TF activity and thrombin generation through combined deficiencies in tissue factor pathway inhibitor (TFPI+/) and reduced thrombomodulin function (TM ${ }^{\text {pro/pro }}$ ) exhibit fibrin deposition in the liver and cerebral microvasculature.[12] Together, these findings suggest cellular regulation of procoagulant activity is a central mechanism dictating fibrin formation and have important implications for the potential value of TF inhibition in preventing thrombosis.

\section{Contributions of Plasma to Thrombin Generation, and Fibrin Formation, Structure, and Stability}

Subsequent to TF exposure, plasma proteins fuel the generation of thrombin and production of fibrin. The profound role of plasma protein concentration and composition is inherently implied by studies demonstrating abnormal clot structure and stability in plasma from patients with hemostatic and prothrombotic disorders. For example, both hemophilia A and B plasmas exhibit reduced thrombin generation, a prolonged onset and reduced rate of fibrin formation, and produce clots consisting of a coarse, permeable network of abnormally thick fibrin fibers. $[13,14]$ In hemophilia, the fibrin network deficiency results from abnormal (reduced) thrombin generation and not from abnormalities within the fibrinogen molecule itself. In contrast, patients with certain fibrinogen mutations (dysfibrinogenemia) often present with bleeding and/or thrombotic complications resulting not from abnormal thrombin generation, but rather directly from aberrant conversion of fibrinogen to fibrin or abnormal fibrin network properties. The fibrinogen mutation A $\alpha$ R554C (Dusart) is a well-characterized example of thrombosisassociated dysfibrinogenemia that produces thin fibers in overly-dense networks that are resistant to fibrinolysis and mechanical deformation.[15] Dysfibrinogenemias may also contribute to morbidity following pulmonary embolism. In an elegant pair of studies, Morris et al. showed plasma clots from patients with chronic thromboembolic pulmonary hypertension (CTEPH) exhibit increased fibrin stability and that these patients have a high incidence of fibrinogen mutations.[16,17] The authors concluded the fibrinogen mutations directly caused increased fibrin network stability in these patients and contributed to the development of CTEPH. These findings suggest abnormal network stability may be a broad mechanism contributing to post-thrombotic complications in other situations as well. 
Recent studies have demonstrated abnormal fibrin structure and/or fibrin network function in plasma clots from patients with diabetes[18-20], idiopathic venous thromboembolism[21], instent thrombosis[22], and myocardial infarction[23,24], and individuals exposed to cigarette smoke[25,26]. Because most of these studies utilized clotting assays initiated with exogenous addition of low thrombin concentrations $(\sim 5 \mathrm{nM})$ that may have activated cofactors and triggered endogenous thrombin generation during the assay, it is not yet known whether the irregular fibrin networks produced by these plasmas resulted from abnormal thrombin generation and/or directly from altered fibrinogen function. For example, two recent independent studies have demonstrated abnormal fibrin properties in clots formed from plasma isolated from smokers. Undas et al.[26] initiated clotting with low thrombin and observed reduced clot permeation and reduced fibrinolysis of plasma clots from smokers compared to healthy never-smokers. While these changes were associated with the level of fibrinogen and markers of oxidative stress[26] abnormal thrombin generation may have also contributed to the abnormal clots. In the second study, Barua et al.[25] initiated clotting by adding a high concentration of exogenous thrombin to plasma. Under these conditions, it is unlikely endogenous thrombin generation occurred during the rapid reaction time course. Thus, the overly dense networks observed in clots from smokers in their study likely resulted directly from abnormal fibrin(ogen). Further studies are warranted to distinguish abnormal thrombin generation from abnormal fibrinogen in smokers, as well as in plasmas from other patients with prothrombotic history.

\section{Conclusions and Future Directions}

The current wealth of evidence suggests abnormal fibrin formation, structure, and stability are biomarkers for, and potentially pathogenic mechanisms contributing to, hemostatic and thrombotic disorders. Therefore, agents that directly or indirectly modify fibrin structure or stability may be viable targets for hemostatic and antithrombotic therapies. Although this review has been limited to the role of procoagulant activity in fibrin formation, it is important to note additional cellular and soluble influences on fibrin formation and stability, including expression of integrins, pro- and anti-fibrinolytic activities, and factor XIII that crosslinks the fibrin network. The relative roles of these and other properties of cells, plasma, and blood flow in fibrin deposition and stability remain important areas for future investigations.

\section{Acknowledgments}

The authors thank Kellie R. Machlus, Laura D. Gray, and Dr. Robert A. Campbell for valuable discussions on fibrin function in hemostasis and thrombosis.

The authors are supported by grants from the National Institutes of Health (HL094740 to ASW and T32ES007017 to MMA), the Gustavus and Louise Pfeiffer Foundation (ASW), the American Heart Association (ASW), and the National Hemophilia Foundation (ASW).

\section{Abbreviations}

$\begin{array}{ll}\text { TF } & \text { tissue factor } \\ \text { TNF } \alpha & \text { tumor necrosis factor-alpha } \\ \text { CTEPH } & \text { chronic thromboembolic pulmonary hypertension } \\ \text { TFPI } & \text { tissue factor pathway inhibitor } \\ \text { TM } & \text { thrombomodulin }\end{array}$




\section{References}

1. Weisel JW. Fibrin assembly. Lateral aggregation and the role of the two pairs of fibrinopeptides. Biophys J 1986;50(6):1079-93. [PubMed: 3801570]

2. Nair CH, Shah GA, Dhall DP. Effect of temperature, $\mathrm{pH}$ and ionic strength and composition on fibrin network structure and its development. Thromb Res 1986;42(6):809-16. [PubMed: 3726801]

3. Glover CJ, McIntire LV, Brown CH 3rd, Natelson EA. Rheological properties of fibrin clots. Effects of fibrinogen concentration, Factor XIII deficiency, and Factor XIII inhibition. J Lab Clin Med 1975;86 (4):644-56. [PubMed: 1176815]

4. Collet JP, Park D, Lesty C, Soria J, Soria C, Montalescot G, et al. Influence of fibrin network conformation and fibrin fiber diameter on fibrinolysis speed: dynamic and structural approaches by confocal microscopy. Arterio Thromb Vasc Biol 2000;20(5):1354-61.

5. Hoffman M, Monroe DM, Roberts HR. Cellular interactions in hemostasis. Haemostasis 1996;26(suppl 1):12-16. [PubMed: 8904166]

6. Tremoli E, Camera M, Toschi V, Colli S. Tissue factor in atherosclerosis. Atherosclerosis 1999;144 (2):273-83. [PubMed: 10407489]

7. Del Conde I, Shrimpton CN, Thiagarajan P, Lopez JA. Tissue-factor-bearing microvesicles arise from lipid rafts and fuse with activated platelets to initiate coagulation. Blood 2005;106(5):1604-11. [PubMed: 15741221]

8. Ovanesov MV, Ananyeva NM, Panteleev MA, Ataullakhanov FI, Saenko EL. Initiation and propagation of coagulation from tissue factor-bearing cell monolayers to plasma: initiator cells do not regulate spatial growth rate. J Thromb Haemost 2005;3(2):321-31. [PubMed: 15670039]

9. Campbell RA, Overmyer KA, Bagnell CR, Wolberg AS. Cellular procoagulant activities dictate clot structure and stability as a function of distance from the cell surface. Arterio Thromb Vasc Biol 2008;28:2247-54.

10. Campbell RA, Overmyer KA, Selzman CH, Sheridan BC, Wolberg AS. Contributions of extravascular and intravascular cells to fibrin network formation, structure, and stability. Blood 2009;114(23):4886-96. [PubMed: 19797520]

11. Herbert JM, Savi P, Laplace MC, Lale A. IL-4 inhibits LPS-, IL-1 beta- and TNF alpha-induced expression of tissue factor in endothelial cells and monocytes. FEBS Lett 1992;310(1):31-3. [PubMed: 1526281]

12. Maroney SA, Cooley BC, Sood R, Weiler H, Mast AE. Combined tissue factor pathway inhibitor and thrombomodulin deficiency produces an augmented hypercoagulable state with tissue specific fibrin deposition. J Thromb Haemost 2008;6:111-7. [PubMed: 17973652]

13. He S, Blomback M, Jacobsson Ekman G, Hedner U. The role of recombinant factor VIIa (FVIIa) in fibrin structure in the absence of FVIII/FIX. J Thromb Haemost 2003;1(6):1215-1219. [PubMed: 12871322]

14. Wolberg AS, Allen GA, Monroe DM, Hedner U, Roberts HR, Hoffman M. High dose factor VIIa enhances clot stability in a model of hemophilia B. Brit J Haematol 2005;131(5):645-55. [PubMed: 16351642]

15. Collet JP, Woodhead JL, Soria J, Soria C, Mirshahi M, Caen JP, et al. Fibrinogen Dusart: electron microscopy of molecules, fibers and clots, and viscoelastic properties of clots. Biophysical Journal 1996;70(1):500-10. [PubMed: 8770228]

16. Morris TA, Marsh JJ, Chiles PG, Auger WR, Fedullo PF, Woods VL Jr. Fibrin derived from patients with chronic thromboembolic pulmonary hypertension is resistant to lysis. Am J Respir Crit Care Med 2006;173(11):1270-5. [PubMed: 16514114]

17. Morris TA, Marsh JJ, Chiles PG, Magana MM, Liang NC, Soler X, et al. High prevalence of dysfibrinogenemia among patients with chronic thromboembolic pulmonary hypertension. Blood 2009;114(9):1929-36. [PubMed: 19420351]

18. Jorneskog G, Hansson LO, Wallen NH, Yngen M, Blomback M. Increased plasma fibrin gel porosity in patients with Type I diabetes during continuous subcutaneous insulin infusion. J Thromb Haemost 2003;1(6):1195-201. [PubMed: 12871319]

19. Dunn EJ, Ariens RA, Grant PJ. The influence of type 2 diabetes on fibrin structure and function. Diabetologia 2005;48(6):1198-206. [PubMed: 15864538] 
20. Undas A, Szuldrzynski K, Stepien E, Zalewski J, Godlewski J, Tracz W, et al. Reduced clot permeability and susceptibility to lysis in patients with acute coronary syndrome: effects of inflammation and oxidative stress. Atherosclerosis 2008;196(2):551-7. [PubMed: 17640649]

21. Undas A, Zawilska K, Ciesla-Dul M, Lehmann-Kopydlowska A, Skubiszak A, Ciepluch K, et al. Altered fibrin clot structure/function in patients with idiopathic venous thromboembolism and in their relatives. Blood 2009;114(19):4272-8. [PubMed: 19690336]

22. Undas A, Zalewski J, Krochin M, Siudak Z, Sadowski M, Pregowski J, et al. Altered plasma fibrin clot properties are associated with in-stent thrombosis. Arterioscler Thromb Vasc Biol 2009;30(2): 276-82. [PubMed: 19910643]

23. Fatah K, Silveira A, Tornvall P, Karpe F, Blomback M, Hamsten A. Proneness to formation of tight and rigid fibrin gel structures in men with myocardial infarction at a young age. Thromb Haemost 1996;76(4):535-40. [PubMed: 8902992]

24. Collet JP, Allali Y, Lesty C, Tanguy ML, Silvain J, Ankri A, et al. Altered fibrin architecture is associated with hypofibrinolysis and premature coronary atherothrombosis. Arterioscler Thromb Vasc Biol 2006;26:2567-73. [PubMed: 16917107]

25. Barua RS, Sy F, Srikanth S, Huang G, Javed U, Buhari C, et al. Effects of cigarette smoke exposure on clot dynamics and fibrin structure: an ex vivo investigation. Arterioscler Thromb Vasc Biol 2009;30(1):75-9. [PubMed: 19815816]

26. Undas A, Topor-Madry R, Tracz W, Pasowicz M. Effect of cigarette smoking on plasma fibrin clot permeability and susceptibility to lysis. Thromb Haemost 2009;102(6):1289-91. [PubMed: 19967167] 


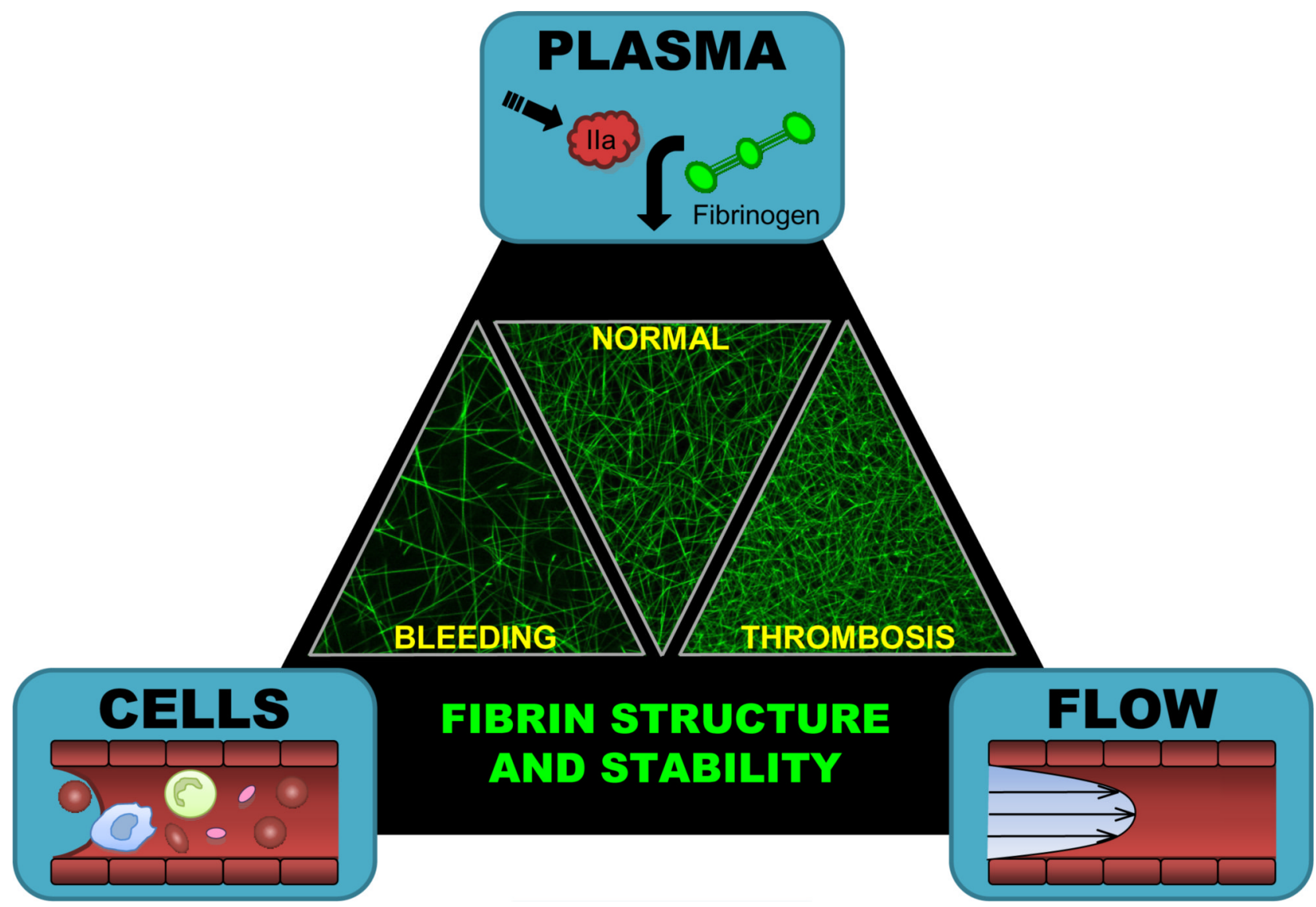

Figure 1. Contributions from cells, plasma, and blood flow (Virchow's Triad) regulate fibrin formation and therefore, fibrin network structure and stability Laser scanning confocal micrographs show recalcified, platelet-poor plasma (hemophilia A, normal, and $200 \%$ fibrinogen from left to right, respectively) spiked with AlexaFluor-488labeled fibrinogen $(10 \mu \mathrm{g} / 120 \mu \mathrm{L}$ sample $)$ and clotted by TF-bearing monocytes. Abnormallycoarse networks of thick fibers are associated with an increased risk of bleeding, whereas overly-dense networks of thin fibers are associated with an increased risk of thrombosis. Characterizing the specific mechanisms by which cells, plasma and blood flow regulate fibrin structure and stability is critical for understanding hemostasis and identifying effective targets for hemostatic and antithrombotic therapies. 